\title{
Dialectal Movies and Heterogeneity of Contemporary Culture
}

\author{
Shen Jiang \\ Cultural Studies, College of Arts, University of Canterbury \\ Christchurch, New Zealand \\ Tel: 86-10-5821-3182Ｅ-mail: jiangshen6206@gmail.com
}

\begin{abstract}
To start a research on the application of dialect in movies and their formation causes and social functions, we must place the questions into specific social and cultural background and examine the relations between dialect, mainstream language and the cultural views of audiences. This paper attempts to take Chinese movies as a starting point to discuss heterogeneity issues in filmic culture by tracing back the history of dialect development and its contemporary cultural conditions. Such thought roots in two aspects. One is "verfremdungs effect of cultural heterogeneity" of dialects and the second is "the multiple natures of cultural heterogeneity".
\end{abstract}

Keywords: Dialect, Cultural heterogeneity, Postmodernity, Beijing opera

\section{The cultural connotation under dialect context}

"Dialectal movie" is a concept formed due to the monopole position of mandarin in China. Hence, it is a relative concept rather than a type of movies. What is more, in history, the concept of dialect is also relative. For example, compared to Zhongyuan culture in core areas (Jianghuai area and Yellow river area) at that time, Lyric Song of Yuan Dynasty, a typical literature pattern of Yuan Dynasty, could be counted as a dialect song. It is not until the time Ming Cheng $\mathrm{Zu}$ moved the capital to Beijing, the position of northern dialect was constantly consolidated and became the communication model that has political core influence. From then on, the commonly used pronunciation habits, through the cultural patterns that are suitable for the artistic tastes of common people, such as Ming and Qing novels, dramas and songs, folk melodies and arts, and Pingshu (a monologue discussing historical events), gradually evolved to be the mandarin in modern literature. Therefore, as a commonly used pronunciation standard, mandarin originally developed from northern dialect. Seeing from the modern cultural equilibrium and diversity, when one commonly used language develops, in cultural art, towards one "pole" or "end" to certain extent, the other end of the cultural scale will certainly react. In postmodernist literature, such reaction shows itself in a deep mode of interlaced two poles; while in the globalization of culture (that is certain type of postmodernist culture), it shows itself as an extensive, diversified, easy and exoteric literature deconstruction tendency (Note 1). If so, in developing countries where tradition and modern phenomenon co-exist and which are deeply influenced by cultural colonialism (Note 2) and globalization, it is no wonder that dialect, as an important element that has rich sound images, becomes a focus in topics of the diversity of Chinese movies.

The fuse for the upsurge of dialectal movies is Crazy Stone directed by Ning Hao in 2006. This movie arouses the interests of various comment fields due to its explosive box office, many of whom pay special attention to the application of dialect in this movie. After the success of this movie, a lot of ideas with dialects as the main selling points were put forward for domestic movies. Even, some articles took other characteristic Chinese dialect movies as examples to emphasize the ticket rallying point of dialect, based on which this paper transfers the discussion of dialect in movies to the vision of cultural comment and tries to combine the diversified application of dialect in movies with the contemporary cultural development mode to make a basic analysis.

Now that we see "dialect" as a relative concept, to discuss dialect in movie culture, we must first explore the relationship between dialect and main stream speech model. As a matter of fact, in contemporary movie art, the relationship between mandarin and dialect is not two confronting poles that are tit for tat and are not of crossing-complementary relationship where one grows and the other eliminates, either. Their co-existence is determined by the demands of movies and hearings on the differences of the two. The demands come from two aspects. One is that movie makers choose the description language differences to express images and the other is audiences' preference on their hearing experience related to "the heterogeneity of languages". However, generally speaking, the images of movie makers and the preference of audiences will ultimately (necessarily) become consistent with each other. Otherwise, misunderstanding will be generated. The consistency of the images and preference should also focus on the analysis on "heterogeneity". The heterogeneity by languages has long been applied in performance art. In the late Qian Long period 
of Qing Dynasty, Hui Ban drama entered the capital city, which brought the flourishing of Beijing Opera. At the beginning of Min Guo, Beijing Opera had become a common entertaining art in northern China and gradually extended to southern cities, such as Shanghai and Guangzhou. At present, the "Hui Aria", originated from Anqing, Anhui province, still exerts significant influence on Beijing Opera aria, which could be considered as a typical example to show the long-living-and-flourishing of dialect in performance art. Although Beijing opera originated from Hui aria, why, after hundreds of years of evolution, could this dialect aria be retained by a strange melody and be promoted? A major reason for it is that the heterogeneity of dialect brings audience with "verfremdungs effect lure in hearing feelings". The majority melodies of Beijing opera are about the ancient historical stories with Zhongyuan culture as the background. For the Man people levels of Qing dynasty, these stories are foreign culture. Then, when accepting foreign stories, these audiences at the earlier stage needed a different aria from northern dialect to meet their demands on the imagination of foreign culture, which is also the first level effect of verfremdungs effect lure. At the late stage of Qing dynasty, the Man and Han culture were gradually combined. The offspring of Beijing opera were influenced by capital city culture and the status of Hui aria was challenged. However, because the audience groups gradually become common, Hui aria, as a stage art language higher than common people's life, continued to be favoured and loved by audiences, which is the second level of verfremdungs effect. After Min Guo period, when the influence of Beijing opera extended to the entire nation and when Beijing opera was introduced to foreign countries as the quintessence of China, the aria of Beijing opera was regarded as a pure and mature stage art tradition and was retained. On one hand, it catered for common people's entertainment and on the other hand, as the "heterogeneity object" of $4^{\text {th }}$ May New Culture, the tradition of Beijing opera was also for people to criticize and to recall, which is the third level of verfremdungs concept. It is not hard to see that to do research on the application of dialect in performance and film arts, we must place the specific problems into material social and cultural background and analyze the Game relationship among dialect, mainstream discourse, and the cultural tastes of audiences.

Just as stated before, in modern Chinese society where tradition, modernity and region nature and globalization coexist, the culture game of dialect seems to be extremely complicated (Wang, 2001). At the present stage, it will not conform with the contemporary social and cultural requirements if we put all "dialect movies" into one category and to see it as a whole (Byron, Allen Harold and Linn, Michael D., 1986). Therefore, I have to divide the discussion on the "heterogeneity" of dialect into two parts: one is, based on the transfer from tradition to modernity, the "verfremdungs effect of heterogeneity" formed by the deeply interlacing between dialect and commonly used language and the other is, based on the exceeding development of certain modernity under the influence of globalization process and cultural colonialism, the "the multiple natures of heterogeneity" formed by bricolage and putting-together among dialects.

\section{The verfremdungs effect of heterogeneity}

"Verfremdungs sense", among the language qualities caused by dialect, is conducive to audiences to form in their minds the special imagination images on heterogeneity life (Dai, 2007). Compared with real life experience, the interest of audiences usually tends to focus on the imagination images of heterogeneity. For example, when we watching foreign movies, we prefer to listen to the original dialogues and read the captions and then gradually discard the demand on dubs, which indicates that the imagination images caused by the heterogeneity are more attractive to us. There are many kinds of imagination images, such as the aforementioned "Hui Aria", which offers people with difference heterogeneity imagination images at different historic periods (such as the imagination images on foreign lands, the imagination images on stages which are beyond life, and the imagination images on the criticism of traditional culture or on memory type); For another example, in movies on significant historic subjects produced after the reform and opening up (such as Da Jue Zhan and Kai Guo Da Dian), the political characters (Mao Zedong, Zhou Enlai, and Jiang Jieshi) spoke their dialects, which offers audiences with true historic imagination images; through the dialect of Fenyang, Shanxi province, the movies directed by Jia Zhangke at his earlier period (such as Xiao Wu and Ren Xiao Yao, and etc) offers typical regional cultural imagination images. However, no matter how complicated it is, in post traditional or modern literature, its "heterogeneity" mod could hardly deviate from a kind of deep verfremdungs effect, which is the pursuit for deep realistic imagination. It has to be made clear that the concepts of "heterogeneity", "Verfremdungs" and "imagination images" do not conflict with the modernism thought advocated by realistic films. The modernism in movies must keep itself from the actual life at a distance or separation level so that the "beauty" and "meaning" could be generated. Therefore, for modern reality, the only way to maintain the depth of reality is to construct and keep a deep difference and verfremdungs (Wang, 2001). For example, at the beginning of the movie Mobile Phone (Shou Ji), the protagonist, Yan Shouyi in his early young, was presented as nostalgia on the screen. The deepest impression on it should be the asking sound in Henan dialect, "Niu Sanjin, Niu Sanjin, your wife is Lv Guihua. Lv Guihua let me ask you whether you will get back home recently." The application of dialect deepens the reality recognition degree of audiences on old imagination images, which also provides a comparison and reference imago for the description on the superiority and convenience of modern information spreading in movies ( $\mathrm{Lu}, 2007)$. Therefore, although this period has passed by, because of verfremdungs sense brought by the sound element (the dialect from the loudspeaker), it is very realistic. There are other similar examples. In Peacock, the Henan Anyang dialect is used throughout the film, and in Mei Shi Tou 
Zhe Le, Tianjin dialect is used. In modernism frame, the application of dialect in movie products always following the principle of "being close to realistic imagination images" and constantly meet the demands of audiences on modern aesthetics, "from but beyond life".

\section{The multiple natures of heterogeneity}

However, beyond modern reality, the disequilibrium of the development of Chinese contemporary culture forces us to consider the exceeding elements of cultures that are connected with international level and are influenced by globalization (Chen, 2004), which is also another element of dialect in contemporary movie culture comparison, "the multiple natures of heterogeneity". Although we are reluctant to admit that Chinese culture shows certain post modern features, we, incorporated into global culture system, could not deny the possibility to make use of this global culture theory to explain contemporary Chinese culture. Because post modernism does not belong to the types of culture, but is the comprehensive representation of global culture interaction. In areas where culture awareness develops ahead of time, people could not just follow strictly modernism economy basis and could not ignore the western "post theory" that comes like storms. On the contrary, the awareness of the consumption, aesthetics and life of post modernism has already penetrated into the life of the public in China through modern economy and media means. The concept of "the multiple nature of heterogeneity" originates from the pilot of post modernism thought, Foucault (Foucault, Michel,1969). Foucault pointed out that items do not have nature or their natures are formed by its accumulation of the heterogeneity with items. From Foucault's words, we could deduce the following features of post modern culture; firstly, in post modern literature, people tend to discard the deep thinking pattern based on two dimensional opposition and choose to the anti-deep, shallow and complanation of idea awareness (Black, 2002); secondly, because of the losing of trust on nature, the direction of literature is not that important and could not be found anywhere. Therefore, the "polarity" of "duality" does not exist anymore and is replaced by the filling, mixing and patching up of multi-culture (Dennison, Stephanie and Son, Hwee Lim, 2006); thirdly, in post industrial society, as the main body of society, human beings are dissimilated and the freedom of spirit fade out in the free bodies (Kieslowski, 1999) and gradually becomes of the "machines" of consumption.

Therefore, when we choose a post-modernism view point and put the sound imago "dialect" under contemporary trend, the meanings represented by the heterogeneity of dialects is not just the "Verfremdungs effect" of modernism, which is shown in the "disappearance of nature". Just as we described, in post modern cultural awareness, the deep nature thoughts disappear. The dialect that originally exists in realistic context and represents realistic Verfremdungs sense (realistic effect) suddenly loses its aim and direction nature (in movie works, dialect loses its dependent body, then lose its objective positions, and the necessity of existence disappears); what has gained is the interest on its appearance. Therefore, dialect re-starts its road and as an independent object, it replaces the inherent nature (or we could directly say, it replaces the essence of nature) and appears in modern Chinese movies. In post modern movie culture, one example that could be used to compare with the main body of "dialect movies" is Visual spectacles produced by Hollywood. We call the movies produced by the western producers with large investment and large design the "big films". The reason is not that the stories of those movies are better than domestic movies and it also does not mean that the art appreciation value or tastes are higher than the movies produced in China. The real reason is that those "big movies" has huge investment in scenes and visual special effect. These effects are more attractive than common movies. However, the auxiliary visual feature that originally is used to describe the main body of the movies becomes the pronoun of this type of movies, which indicates the spirit personality of post modernism, that is to give prominence to visual idea, to neglect the inherent nature of narration depth, to put the attached as the main and to extract full weight from a small part. To put it in other words, in post-modern culture, what attracts audiences in a film is no longer (or not only) the stories, deep images and the impressive ending. As the movie art idea, "visual spectacle" also shoulders the task of main body to attract and impress audiences. Similarly, dialect could also become the main body mark for movies and become a main element to attract Chinese audiences to go to the cinema and consume. When we watch Hollywood grand movies, we neglect the rallying point of stories, plot, stars, and suspense because it brings audiences with visual feelings. We like dialect movies because it brings audiences with language and hearing enjoy to audiences. The hot discussion on dialect movies is also generated under the guide of this kind of thought. Its strategy lies in that the nature of movies is shown through the heterogeneity of dialect. Of course, the superficiality of the idea of post modern culture does not mean it completely discards the problems and depth. In the following part, we will also mention the sense of responsibility and worrying mode of dialect in post modern culture.

After the discussion on relationship between heterogeneity and nature, let us discuss "multiple" nature or the pluralism. For dialects and movies, multi-nature has two concepts. For one aspect, it refers to the representation of nature by the "multi-pattern and patching up" of heterogeneity; for another aspect, it advocates a type of "multi-view point" to treat culture nature. For the first aspect, multi-pattern and patching up is the mark for post modern literature. In recent years, we could see that more and more movies of dialects, such as Gui Zi Lai Le, Not One less, Xun Qiang, Beautiful Big Feet, Mei Ren Cao, and Huan Die. However, compared to Crazy Stone, the biggest difference lies in that the former are regional movies with only single dialect and the latter is the region edge movie with diversified dialect patching up. 
"Regional" does not mean that it has limitation and just means that the space of the stories and the application effect of dialects suit each other; "Regional edge" (Marginalization) concept actually comes from the "geological political aesthetics" by F. Jameson. It mainly discusses the communication, context and conflicts beyond geographical concepts and different regional culture. Therefore, regional edge movie tend to the mixture of certain spaces and regions and provides the chance of creation for the application of dialect. Although Crazy Stone, the main scene place is Chongqing, we found that the application of dialect in the movie is not only the Chuanyu dialect. We could hear the dialects of Baoding, Qingdao, Jinan and Tianjin, even Cantonese. No doubt, the diversified dialect patching up and the regional feature shown by multi elements do not fit each other. However, due to the existence of multiple nature, the space imagination of audiences exceed the geography limit is extended unlimitedly and finally, the accumulation and mixture of dialect result in that the relevant multiple element space conflicts and shocks in the minds of audiences. In addition, the patching up of dialects obliterates the rationality of the fitness itself and regional concept, which is also the exiling nature of contemporary culture and the representation that floats on idea. Even, we could call this phenomenon "regional edge dialect aesthetics". If we consider at a wider range, the application of languages in Journey to the West could also be compared. In this move, although there is not much application of dialects, it uses English, Japanese and many unrelated words, which reflects the thinking of Hong Kong movies on globalization and cultural colonialism. In the dialect movies of China whether the accumulation of many dialects indicates that the entire Chinese culture tends to have certain trend or the expediting crossing and combination among Chinese regional culture? For another aspect, the languages in Journey to the West not only reflect the distrust of post modern literature on the logic of languages and their rationality degree. At the same time, it shows that in post industrial society, human beings, originally as the main body of languages, experience heterogeneity crisis, which is that human beings gradually lose their spiritual main body position in post modern society. In this society full of imagination and desire, human beings unconsciously change from the main body of consumption to the consumption machine. Therefore, from spirit to behaviour, all of the human beings could be incorporated into the unconscious "consumption" actions. So do languages. If we explain "Wu li tou" as our consumption on languages, then whether the dialect mixture that "has lost the rationality fitness of regional feature" could be considered as a feast of dialect for audiences to consume? Similar large-scaled consumption on dialects is frequently seen in movies, such as The Stories of Cooking Team (Chui Shi Ban De Gu Shi) and My Own Swordsmen (Wu Lin Wai Zhuan). Of Course, to use consumption mode to explain the irrationality expression of language in texts is just a wide method for culture criticizing. For particular problems, we need to make specific analysis. For example, in Ni Qiu Ye Shi Yu, the mixture of dialects also appears. However the mixture of dialects in this movie has reasons. It mainly represents the life of labour workers from other areas working in Beijing. Therefore, we could not think that this movie represents the post modern culture miss position and mixture between dialects and regions just because the character performed by Ni Ping speaks Jiaodong dialects and the story occurs in Beijing. As a matter of fact, most of the application of dialects in movies still remains at the realistic level of modern literature (Lin, 2005).

Let us turn back and see the other aspect of "multiple nature". We will treat the culture character of dialect phenomenon from multiple view points. As a matter, it is not a cultural strategy but it advocates a kind of multi-elements and open culture criticism. For example, in contemporary movie art dialect game, there exists cultural theory of "difference" and "sameness". For one aspect, according to the multi-element post modern literature thought, we could explain the existence of dialect in certain movies as follows. It is the explanation on the recognition of audiences on language because the heterogeneity of dialect does place the challenge against the single polarity of languages. Hence, it is regarded as the cultural representation of searching for heterogeneity; for another aspect, if we could uncover the idea of "the diversified nature of languages" and careful probe into the connotation of context, we could surprisingly find out that all of use are sharing the same meaning. Audiences of different regions might have similar cultural tastes, attitude, and concept. The difference of culture is just nominal, and dialect is just a camouflage. It may raise a question for us. Is the hot trend of dialects in movies the last memory on heterogeneity left by multi-culture? Whether it is true that what the multi-culture value ideas depend on in dialect movies is not the rich and diversified literature connotation but reflects the culture and identifies recognition of Chinese audiences which is tending to be the same? Seeing from a macro-perspective, the contemporary movie hot rend also reflects the self anxiety of post modernism and is the anxiety on globalization culture colonialism and sameness. Therefore, it could be concluded that although they are all the movie culture criticism on dialects and they all apply multi-element culture view point, the conclusions are opposite, which is also where the "multiple nature" of dialect in culture field lies in. Actually, the key difference of the opposite theory lies in that: one part thinks that dialect is helpful for the movie art develops towards multi-culture direction and is pursuing difference; However, the other party thinks that under the disguise of multi-culture, dialect pursues the even nature of language meanings and puts the application of languages under single polar awareness mode with multi-element shape but with no true common flourishing. Although it is the best reflection of sameness trend of culture, it is not good for stopping the nibbling of globalization culture colonialism tend on Chinese region culture diversities. Facing with this dilemma, objectively, we think that dialect is experiencing an independent game in movie culture; subjectively, we wish it develops towards "discarding sameness and pursuing peace. The opposite word of sameness is peace rather than difference. For globalization and national culture, the win-win ending is not sameness but is peace, that is having 
difference in sameness and pursuing peace in difference and being win-win. The game of dialect in contemporary culture is also the same reason.

Note: This paper is translated by Lixue.

\section{References}

Wang, Yuechuan. (2001). Post Modern and Post Colonialism in China. Beijing: Capital Normal University Press.

Byron, Allen Harold and Linn, Michael D. (1986). Dialect and Language Variation. Orlando, Fla: Academic Press.

Dai, Ling. (2007). Discussion on the values of dialect in movie creation. Jianghan University Paper. 3

Wang, Yuechuan. (2001). Post Modern and Post Colonialism in China. Beijing: Capital Normal University

Lu, Sheldon H. (2007). Chinese Modernity and Global Biopolitics : Studies in Literature and Visual Culture. Honolulu: University of Hawai'i Press.

Chen, Xiaoming. (2004). Post Modernism. Zhengzhou: Henan University Press.

Foucault, Michel. (1969). L’Archéologie du Savoir, Paris.

Black, Joel. (2002). The Reality Effect: Film Culture and the Graphic Imperative. New York London: Routledge.

Dennison, Stephanie and Son, Hwee Lim. (2006). Remapping World Cinema : Identity, Culture and Politics in Film. London; New York: Wallflower Press.

Kieslowski. (1999). Post Modern Culture. Beijing: Central Editing and Translation Press.

Lin, Yong. (2005). Chinese Movies of Cultural Reform Post Ear and Globalization Culture. Beijing: Cultural and Art Press.

Notes

Note 1. Deconstruction tendency refers to the afore mentioned the evolution from modern literature to post modern culture, which is the turning from the clear and two element deep and complicated structure system to the two polar melting, multi-element combination and deep complanation deconstruction strategy.

Note 2. Tao Dongfeng sees cultural colonialism the same as post colonialism. Please refer to Post Colonialism, Post Colonialism Theory and Post Colonial Nature, and Culture Research, 2003-4. 